\title{
Synthesis and Fluorescence Properties of New Ester Derivatives of Isothiazolo [4,5-b] Pyridine
}

\author{
Edward Krzyżak • Małgorzata Śliwińska • \\ Wieslaw Malinka
}

Received: 8 September 2014 / Accepted: 2 January 2015 / Published online: 23 January 2015

(C) The Author(s) 2015. This article is published with open access at Springerlink.com

\begin{abstract}
A two new compounds with potential biologically active were synthesized: ethyl 4-(2H-4,6-dimethyl-3-oxo-2,3dihydroisothiazolo [5,4-b] pyridin-2-yl) butanoate and ethyl 4-(2H-4,6-dimethyl-2,3-dihydroisothiazolo [5,4-b] pyridin-3yloxy) butanoate. The structures of all of the newly formed compounds were identified by elemental analysis, FTIR and ${ }^{1} \mathrm{H}$ NMR. Their optical properties were studied in ethanol and n-hexane by UV-Vis absorption and fluorescence spectroscopy. The ground-state and excited-state properties were investigated using the density functional theory (DFT) and the time-dependent density functional theory (TDDFT) methods. The results showed differences between emission spectra in ethanol and n-hexane solution (solvatochromism) for both new compounds.
\end{abstract}

Keywords Synthesis $\cdot$ Fluorescence $\cdot$ DFT $\cdot$ Excited state

\section{Introduction}

The interest in the fluorescent molecules has steadily increasing in recent years. Fluorescent biomarkers and probes provide in-depth knowledge about biological system. Many scientific articles have focused on the absorption and emission

E. Krzyżak $(\bowtie)$

Department of Inorganic Chemistry, Wrocław Medical University, ul. Borowska 211A, 50-556 Wrocław, Poland

e-mail: edward.krzyzak@umed.wroc.pl

M. Śliwińska • W. Malinka

Department of Chemistry of Drugs, Wroclaw Medical University, ul.

Borowska 211, 50-556 Wrocław, Poland properties of differently substituted benzoxazoles and benzothiazoles because of their high quantum yields. They have a wide range of applications as fluorescent probes and as intermediates for dyes [1-4]. Although a number of papers have been published concerning the fluorescent properties of different heterocyclic systems, isothiazolo $[4,5-b]$ pyridine moiety has not yet been extensively studied.

Here we report the synthesis and fluorescence properties of novel derivatives of isotiazolo $[5,4-b]$ pyridine. Early studies demonstrated that some of isotiazolopyridines containing different substituents have been investigated because of their biological activity. Their activity depends usually on nature of substituents attached to the isothiazole ring. For example, 2-(4-substituted-piperazin-1-ylalkyl)-3-oxoisothiazolo [5,4-b] pyridines display strong analgesic activity $[5,6]$ and moderate antimycobacterial properties [7]. Other authors have also suggested antiagregative action of derivatives of isothiazolo [5,4-b] pyridine [8].

On the other hand, the literature reports examples of antinociceptive agents bearing an alkanoic acid or ester moieties linked to the 3-nitrogen of 2-oxo-3H-benzoxazole ring $[9,10]$. Gulcan and co-workers [10] synthesized 4-(5-chloro2(3H)-benzoxazolon-3-yl) butanoic acid and its ethyl ester with analgesic activity that was higher or comparable to that of aspirin and, what is more, without gastric side effect.

Taking into account the interesting biological activity of isothiazolopyridines and related benzoxazoles, we have described novel ethyl 4-(2H-4,6-dimethyl-3-oxo-2,3dihydroisothiazolo [5,4-b] pyridin-2-yl) butanoate and its 3$\mathrm{O}$-substituted isomer. The aim of this work is to synthesize and investigate the basic fluorescence properties of new compounds. The presence of strong basic and electron deficient pyridine ring in the isothiazolo $[4,5-b]$ pyridine moiety makes these systems different from the better known benzoxazole and benzothiazole rings. 


\section{Experimental}

Materials

All reagents and solvents were purchased from commercial suppliers. Dry solvent was obtained according to the standard procedure. Flash column chromatographic purifications were performed using Sigma-Aldrich 60A silica gel 230-400 mesh. Progress of the reaction was monitored by TLC on silica gel 60 F254-coated TLC plates (Fluka Chemie Gmbh) and visualized by UV light at $254 \mathrm{~nm}$.

Methods and Instruments

The proton nuclear magnetic resonance $\left({ }^{1} \mathrm{H}\right.$ NMR) spectra were recorded on a Brucker $300 \mathrm{Mhz}$ NMR spectrometer using tetramethylsilane (TMS) as internal reference. Chemical shifts are reported as $\delta$ in parts per million (ppm). The samples were prepared by dissolving $5 \mathrm{mg}$ of each form in $600 \mu \mathrm{l}$ of $\mathrm{CDCl}_{3}$.

FTIR spectra were run on a Perkin-Elmer Spectrum Two UATR FT-IR spectrometer. The samples were applied as solids.

Thermal characteristic was carried out on a Mettler Toledo DCS 25 measuring cell with TC15 TA Controller, calibrated with indium to ensure the accuracy of the calorimetric scale. Samples weighing $3 \mathrm{mg}$ were characterized in sealed $40 \mu \mathrm{L}$ aluminium pans and subjected to thermal analysis under a flowing argon atmosphere $\left(30 \mathrm{~cm}^{3} \mathrm{~min}^{-1}\right)$, using heating rate of $5^{\circ} \mathrm{C} \min ^{-1}$.

Elemental analyses for carbon, nitrogen and hydrogen were carried out on an Carlo Erba NA 1500 analyser and were within $\pm 0.4 \%$ of the theoretical value.

\section{Computational Methods}

The electronic structure calculations were carried out using Gaussian 09 program package [11]. The ground state geometric optimizations was calculated using density functional theory (DFT) with Becke's three-parameter hybrid exchange function with the Lee-Yang-Parr gradient corrected correlation (B3LYP) [12-14] functional in combination with 6-311+G (d, p) basis set. The electronic properties, such as absorption and emission wavelengths, oscillator strengths, were calculated using time-dependent density functional theory at the TDDFT/6-311+G (d, p) level. The hybrid functionals PBE0 [15] were employed in calculations.

\section{Results and Discussion}

Synthesis

Procedure for the preparation of Ethyl 4-(2H-4,6-dimethyl-3oxo-2,3-dihydroisothiazolo [5,4-b] pyridin-2-yl) butanoate (1) and Ethyl 4-(2H-4,6-dimethyl-2,3-dihydroisothiazolo [5, 4-b] pyridin-3-yloxy) butanoate (2) (Fig. 1).

$1,08 \mathrm{~g}$ (6 mmol) of 4,6-dimethyl-3-oxo-2,3dihydroisothiazolo $[5,4-b]$ pyridine [16] was dissolved in an ethanolic solution of sodium ethoxide prepared by the reaction of $\mathrm{Na}^{\circ}(0,14 \mathrm{~g}, 6 \mathrm{mmol})$ with $30 \mathrm{~mL}$ of anh. ethanol. After evaporation to dryness under vacuum, the residue was dissolved in $30 \mathrm{~mL} \mathrm{~N}, \mathrm{~N}$-dimethylformamide and then $0,99 \mathrm{~g}(6,6 \mathrm{mmol})$ of ethyl 4-chlorobutanoate was added, heated for $12 \mathrm{~h}$., cooled to room temperature and poured into $50 \mathrm{~mL}$ ice-water. The precipitate was collected by suction filtration. The residue was chromatograhed [CC; ethyl acetate:cyclohexene:chloroform (2:2:1)]. The fractions containing the product of $\mathrm{R}_{\mathrm{f}}=0,83$ afforded 1,06 $\mathrm{g}$ of $\mathbf{2}$ (yield: $60 \%$ ), whereas fractions of $\mathrm{R}_{\mathrm{f}}=0$, 55 gave additionally $0,53 \mathrm{~g} 1$ (yield: $30 \%$ ).

The final compounds were characterizes by FTIR and ${ }^{1} \mathrm{H}$ NMR methods. Selected results are given below.

1: Anal. $\mathrm{C}_{13} \mathrm{H}_{16} \mathrm{~N}_{2} \mathrm{O}_{2} \mathrm{~S}$ (m.w. 294,39); ${ }^{1} \mathrm{H} \mathrm{NMR}\left(\mathrm{CDCl}_{3}\right) \delta$ : $1,25 \mathrm{t}\left(3 \mathrm{H}, \mathrm{OCH}_{2} \mathrm{CH}_{3}, \mathrm{~J}=7,2 \mathrm{~Hz}\right), 2,03-2,13 \mathrm{~m}\left(2 \mathrm{H}, \mathrm{CH}_{2} \mathrm{CH}_{2}\right.$ $\left.\mathrm{CH}_{2}\right), 2,40 \mathrm{t}\left(2 \mathrm{H}, \mathrm{CH}_{2} \mathrm{CH}_{2} \mathrm{CO}, \mathrm{J}=7,5 \mathrm{~Hz}\right), 2,60 \mathrm{~s}\left(3 \mathrm{H}, \mathrm{CH}_{3}\right), 2$, $74 \mathrm{~s}\left(3 \mathrm{H}, \mathrm{CH}_{3}\right), 3,92 \mathrm{t}\left(2 \mathrm{H}, \mathrm{NCH}_{2}, \mathrm{~J}=7,2\right), 4,12 \mathrm{q}\left(2 \mathrm{H}, \mathrm{OCH}_{2}\right.$ $\left.\mathrm{CH}_{3}, \mathrm{~J}=7,2\right), 6,94 \mathrm{~s}(1 \mathrm{H}, \mathrm{ArH})$. FT-IR (UATR, selected lines): $1720(\mathrm{C}=\mathrm{O}$, ester $), 1670(3-\mathrm{C}=\mathrm{O}) \mathrm{cm}^{-1}$. Anal. Calcd: C, 57, 11 ; H, 6,17; N, 9,52. Found: C, 57,10; H, 6,32; N, 9,35.
Fig. 1 Scheme for the preparation of Ethyl 4-(2H-4,6dimethyl-3-oxo-2,3dihydroisothiazolo [5,4-b] pyridin-2-yl) butanoate (1) and Ethyl 4-(2H-4,6-dimethyl-2,3dihydroisothiazolo [5,4-b] pyridin-3-yloxy) butanoate (2)<smiles>CCOC(=O)CCCOc1nsc2nc(C)cc(C)c12</smiles> 


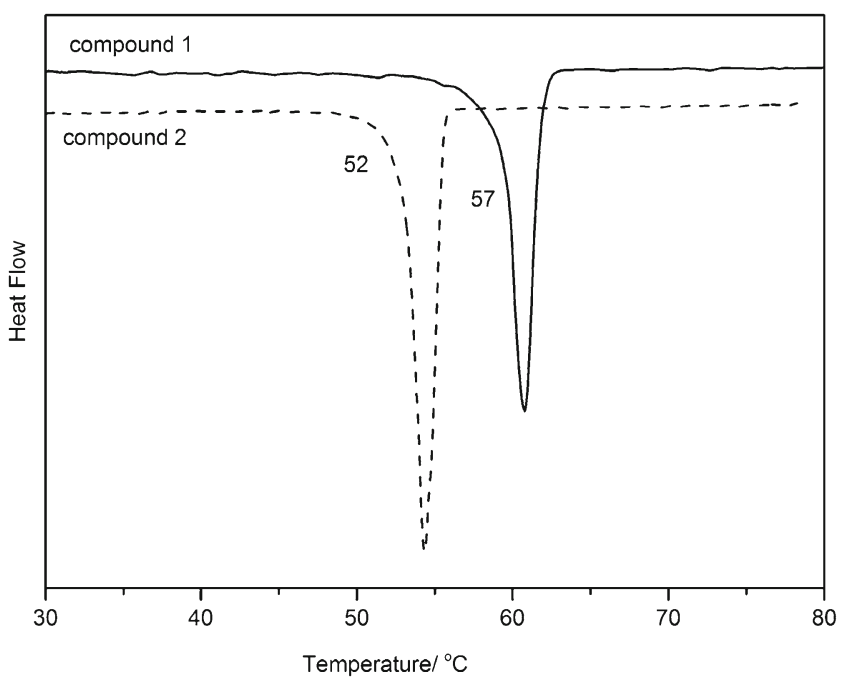

Fig. 2 DSC curves for studied compounds heated at $5{ }^{\circ} \mathrm{C} \min ^{-1}$

2: Anal. $\mathrm{C}_{13} \mathrm{H}_{16} \mathrm{~N}_{2} \mathrm{O}_{2} \mathrm{~S}$ (m.w. 294,39); ${ }^{1} \mathrm{H}$ NMR $\left(\mathrm{CDCl}_{3}\right) \delta$ : $1,25 \mathrm{t}\left(3 \mathrm{H}, \mathrm{OCH}_{2} \mathrm{CH}_{3}, \mathrm{~J}=7,2 \mathrm{~Hz}\right), 2,18-2,24 \mathrm{~m}\left(2 \mathrm{H}, \mathrm{CH}_{2} \mathrm{CH}_{2-}\right.$ $\left.\mathrm{CH}_{2}\right), 2,52 \mathrm{t}\left(2 \mathrm{H}, \mathrm{CH}_{2} \mathrm{CH}_{2} \mathrm{CO}, \mathrm{J}=7,5 \mathrm{~Hz}\right), 2,63 \mathrm{~s}\left(3 \mathrm{H}, \mathrm{CH}_{3}\right), 2$, $66 \mathrm{~s}\left(3 \mathrm{H}, \mathrm{CH}_{3}\right), 4,13 \mathrm{q}\left(2 \mathrm{H}, \mathrm{OCH}_{2} \mathrm{CH}_{3}, \mathrm{~J}=7,2\right), 4,54 \mathrm{t}(2 \mathrm{H}$, $\left.\mathrm{OCH}_{2} \mathrm{CH}_{2}, \mathrm{~J}=6\right), 6,93 \mathrm{~s}(1 \mathrm{H}, \mathrm{ArH})$. FT-IR (UATR, selected lines): $1720\left(\mathrm{C}=\mathrm{O}\right.$, ester $\mathrm{cm}^{-1}$. Anal. Calcd: $\mathrm{C}, 57,11 ; \mathrm{H}, 6$, 17 ; N, 9,52. Found: C, 57,46; H, 6,15; N, 9,52.

Additionally, the compounds were analyzed by differential scanning calorimetry. The DSC trace shows only one thermal effect (Fig. 2). It corresponds to melting process. The melting temperature was determined as $57^{\circ} \mathrm{C}$ for compound 1 and $52{ }^{\circ} \mathrm{C}$ for compound 2 .

\section{UV-vis Absorption Spectra}

The experimental UV-Vis spectra in ethanol and n-hexane for compound 1,2 are shown in Figs. 3 and 4 and their spectra

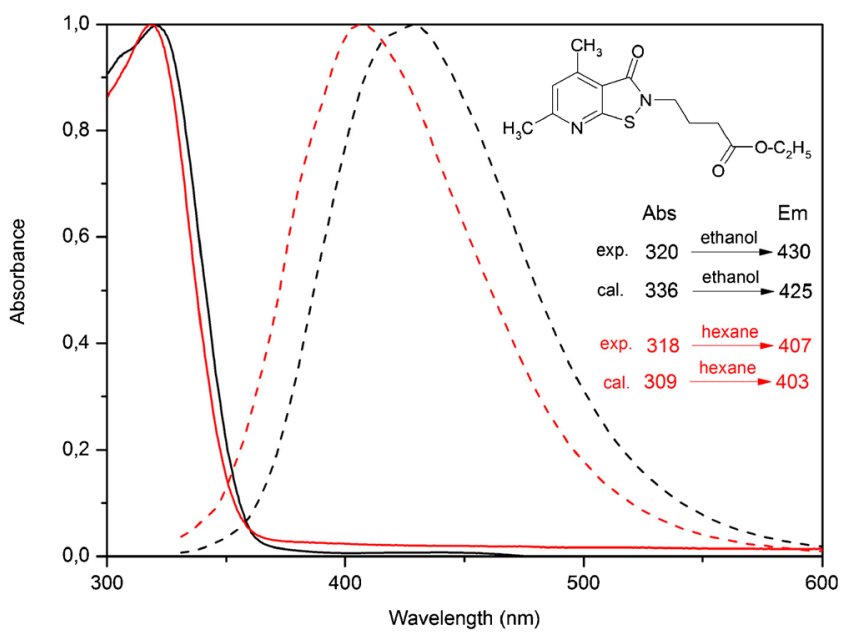

Fig. 3 Normalized UV-Vis (solid line) and emission (dot line) spectra in ethanol (black) and n-hexane (red) solution for compound 1

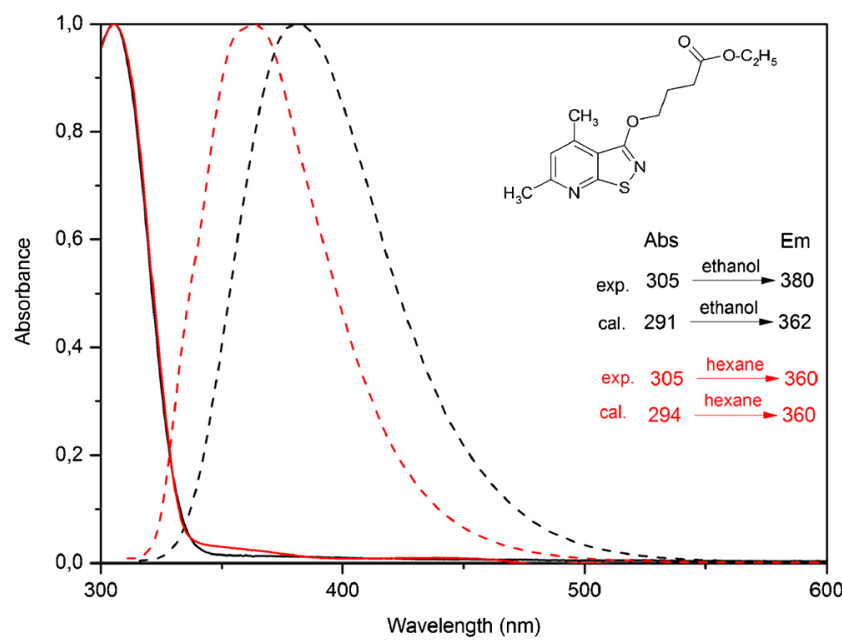

Fig. 4 Normalized UV-Vis (solid line) and emission (dot line) spectra in ethanol (black) and n-hexane (red) solution for compound 2

data are summarized in Table 1. The results showed strong broad absorption bands starting at $365 \mathrm{~nm}$ with maximum at 320 (ethanol) and $318 \mathrm{~nm}$ (n-hexane) for compound 1 and $345 \mathrm{~nm}$ with maximum $305 \mathrm{~nm}$ for compound 2. The calculated absorption maxima values have been found to be 336 (ethanol), $309 \mathrm{~nm}$ (n-hexane) for compound 1 and 291 (ethanol), $294 \mathrm{~nm}$ (n-hexane) for compound 2.

\section{Fluorescence Spectra}

The fluorescence spectra was recorded in ethanol and nhexane at a concentration of $1.0 \times 10^{-5} \mathrm{~mol} \mathrm{dm}^{-1}$. Their emission spectra are shown in Figs. 3 and 4 and their spectra data are summarized in Table 1. The maximal emission peaks of compound 1 are located at $407 \mathrm{~nm}$ in $\mathrm{n}$-hexane solution and $430 \mathrm{~nm}$ in ethanol solution. The fluorescence intensity in ethanol solution is much higher (Fig. 5). The calculated emission maxima values have been found to be 425 (ethanol), $403 \mathrm{~nm}$ (n-hexane) and they are in good accordance with experimental. For compound 2, the maximal emission peaks are located at $360 \mathrm{~nm}$ (nhexane) and $380 \mathrm{~nm}$ (ethanol). The calculated values are 360

Table 1 Experimental and calculated spectra in ethanol and $\mathrm{n}$-hexane solution for Ethyl 4-(2H-4,6-dimethyl-3-oxo-2,3-dihydroisothiazolo [5,4-b] pyridin-2-yl) butanoate (1) and Ethyl 4-(2H-4,6-dimethyl-2,3dihydroisothiazolo [5,4-b] pyridin-3-yloxy) butanoate (2)

\begin{tabular}{|c|c|c|c|c|}
\hline \multirow[t]{2}{*}{ Compound } & \multicolumn{2}{|c|}{$\mathrm{UV}-\mathrm{Vis}$ spectra $\lambda_{\max }(\mathrm{nm})$} & \multicolumn{2}{|c|}{ Fluorescence spectra $\lambda_{\max }(\mathrm{nm})$} \\
\hline & Ethanol & n-hexane & Ethanol & n-hexane \\
\hline 1 & $\begin{array}{l}\text { exp. } 320 \\
\text { cal. } 336\end{array}$ & $\begin{array}{l}\text { exp. } 318 \\
\text { cal. } 309\end{array}$ & $\begin{array}{l}\text { exp. } 430 \\
\text { cal. } 425\end{array}$ & $\begin{array}{l}\text { exp. } 407 \\
\text { cal. } 403\end{array}$ \\
\hline 2 & $\begin{array}{l}\text { exp. } 305 \\
\text { cal. } 291\end{array}$ & $\begin{array}{l}\text { exp. } 305 \\
\text { cal. } 294\end{array}$ & $\begin{array}{l}\text { exp. } 380 \\
\text { cal. } 362\end{array}$ & $\begin{array}{l}\text { exp. } 360 \\
\text { cal. } 360\end{array}$ \\
\hline
\end{tabular}




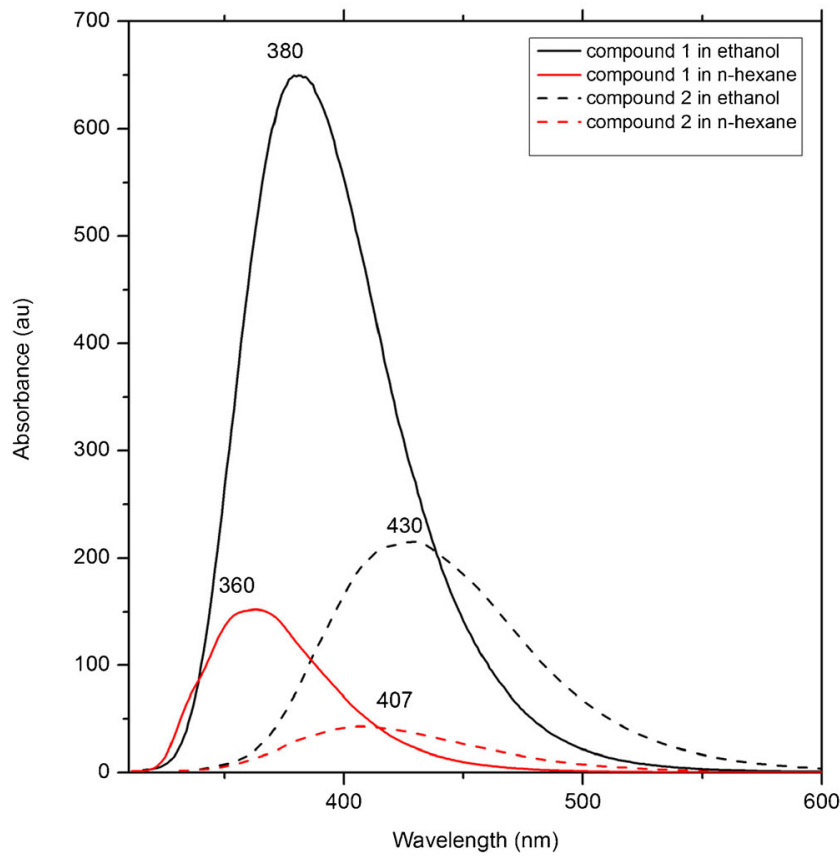

Fig. 5 Experimental emission spectra in ethanol (black) and n-hexane (red) solution for compound 1 (solid line) and compound 2 (dot line) and $362 \mathrm{~nm}$, respectively. The fluorescence intensity in ethanol solution is much higher, similarly as for compound 1 (Fig. 5).

Fluorescence quantum yields were determined in different solvents by using anthracene $(\Phi=0.36$ in cyclohexane) as a reference standard using the comparative method. The fluorescence quantum yields of the synthesized compounds were 0.15 (ethanol) and 0.10 (n-hexane) for 1 and 0.10 (ethanol) and 0.07 (n-hexane) for 2 .

\section{Calculations}

Based on our theoretical results the fluorescent state of both compounds corresponds to the orbital transition from the highest occupied molecular orbital (HOMO) to the lowest unoccupied molecular orbital (LUMO). The atomic orbital compositions of the frontier molecular orbital are sketched in Fig. 6. In the HOMO, the charge density is mainly accumulated on the pyridine ring. In case of the LUMO, more charge density moves to the isothiazole part. The transitions which are observed are assigned as $\pi \rightarrow \pi^{*}$. As shown in Figs. 2 and 3, the value of maximum absorption peaks for
Fig. 6 The plots of HOMO and LUMO orbital contour for molecule 1 and 2

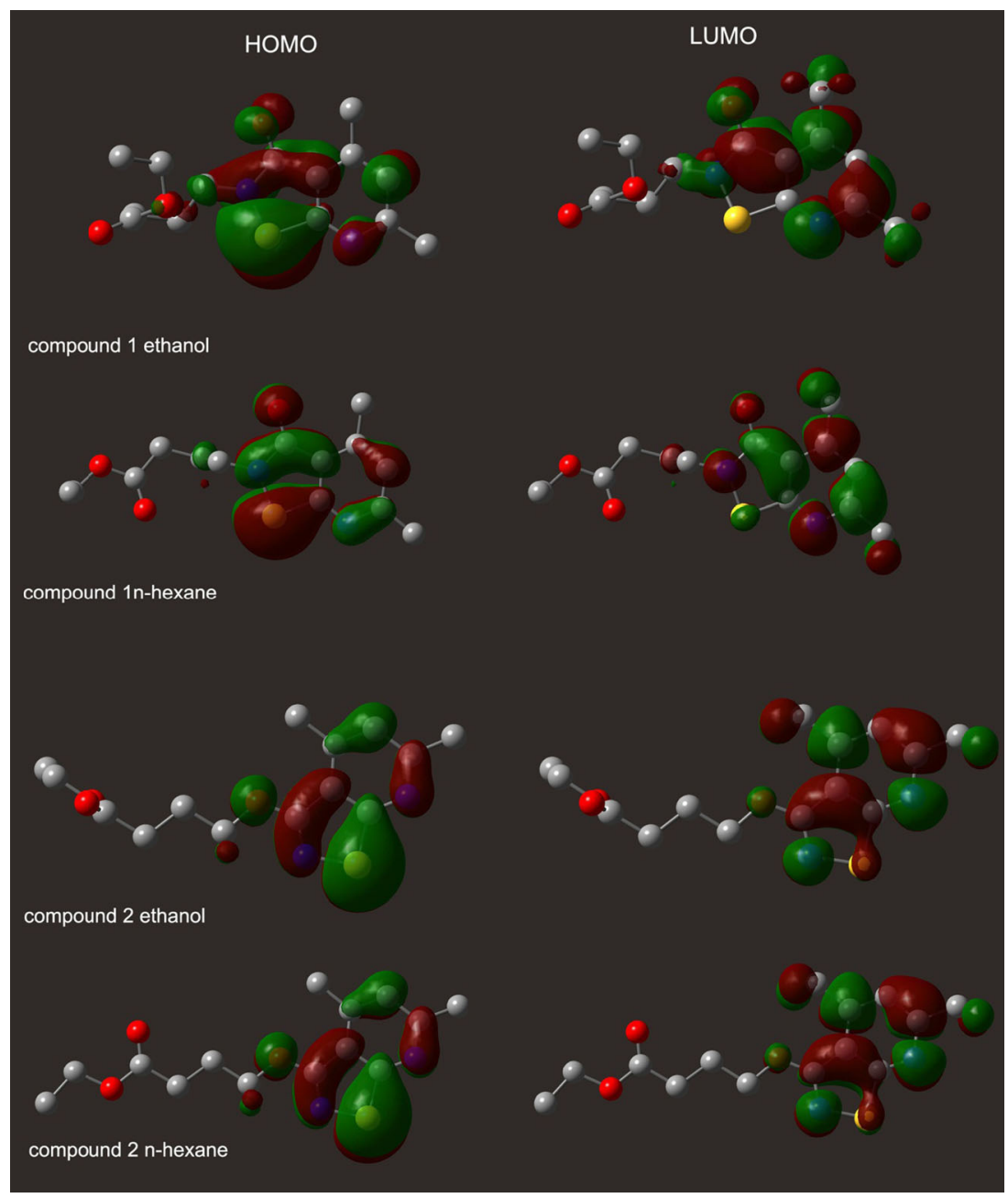


the first band is almost identical in both solutions and different for $\mathrm{N}$-isomer and O-isomer. For both isomers, the fluorescence spectra was found to be dependent on solvent polarity and intensity in ethanol solution is much higher than n-hexane (Fig. 5). As is well known with increasing solvent polarity, the ground state molecule is better stabilized by solvation than the molecule in the excited state (blue shift will result), or better stabilization of the molecule in the first excited state relative to the ground state, with increasing solvent polarity, will lead to positive solvatochromism (red shift). An important parameter is the dipole moment difference between the ground and excited state. The dipole moment calculated within TDDFT formalism for the $\mathrm{N}$-isomer (compound 1) in the ground state is found as $2.05 \mathrm{D}$ in the $\mathrm{n}$-hexane solution, and increases to 2.88 $\mathrm{D}$ in excite state. In the ethanol solution, the dipole moment is slightly higher and increases from 3.26 D (ground state) to 4.25 D (excite state). For the O-isomer (compound 2) the dipole moments are slightly higher: in the ground state 3.27 $\mathrm{D}$ and excite state $4.08 \mathrm{D}$ (n-hexane solution) and $5.80 \mathrm{D}, 6.92$ $\mathrm{D}$, respectively in ethanol solution. The difference between the ground and excited state is rather small in all cases: $\Delta \mu=$ $0.83,0.99,0.81$ and $1.12 \mathrm{D}$, respectively. Those calculations are in good agreement with experimental absorption spectra. However, the emission spectra in ethanol solution is red shifted. A variety of environmental factors affect fluorescence emission, including interactions between the molecule and surrounding solvent. Solvent molecules assist in stabilizing and further lowering the energy level of the excited state by re-orienting around the excited fluorophore and in the results reducing the energy separation between the ground and excited states. Increasing the solvent polarity (ethanol) reduces the solvent effect on the excited state energy level. Our calculation also does not include the intermolecular interactions. Moreover, both isomers have atoms with free electron pairs $(\mathrm{O}$ and $\mathrm{N})$. Therefore the transitions can have mixed character: $\mathrm{n} \rightarrow$ $\pi^{*}$ and $\pi \rightarrow \pi^{*}$, and affect the emission spectra and solvent effect.

\section{Conclusion}

In this work, two new ester derivatives of isothiazolo [4, 5-b] pyridine, compounds with potential biologically active, were synthesized. Their structures were confirmed by FTIR, ${ }^{1} \mathrm{H}$ NMR, elemental analysis techniques. The absorption and emission spectra of titled compounds in ethanol and nhexane solution were studied experimentally and theoretically. The results showed that the fluorescence spectra depends on solution. The emission spectra in ethanol solution is red shifted. The calculated dipole moment increases in excited state and is higher in ethanol than n-hexane solution. Polarity of the solvent also affects the intensity of the emission band.
The results obtained clearly show differences in optical properties of $\mathrm{N}$ - and $\mathrm{O}$-isomer. Due to light emission properties and ease methods of synthesis, the new derivatives may be considered for the development of functional dyes.

Acknowledgments Calculations have been carried out in Wroclaw Centre for Networking and Supercomputing (http://www.wcss.wroc.pl).

Open Access This article is distributed under the terms of the Creative Commons Attribution License which permits any use, distribution, and reproduction in any medium, provided the original author(s) and the source are credited.

\section{References}

1. Guzow K, Szabelski M, Malicka J, Karolczak J, Wiczk W (2002) Synthesis and photophysical properties of 3-[(2-pyridyl) benzoxazol5-yl] alanine derivatives. Tetrahedron 58:2201-2209

2. Esteves CIC, Silva AMF, Raposo MMM, Costa SPG (2009) Unnatural benz-X-azolyl asparagine derivatives as novel fluorescent amino acids: synthesis and photophysical characterization. Tetrahedron 65:9373-9377

3. Ono M, Hayashi S, Kiura H, Kawashima H, Nakayama M, Saji H (2009) Push-pull benzothiazole derivatives as probes for detecting $\beta$-amyloid plaques in Alzheimer's brains. Bioorg Med Chem 17: 7002-7007

4. Mahadevan KM, Masagalli JN, Harishkumar HN, Kumara MN (2014) Synthesis and fluorescence study of some new blue light emitting 3-(1,3-benzothiazol/benzoxazol-2-yl)-2H-chromen-2-ones. Trans Org Chem 1:20-30

5. Malinka W, Sieklucka-Dziuba M, Rajtar G, Zgodzińska W, Kleinrok Z (2000) Synthesis and preliminary screening of derivatives of 2-(4arylpiperazin-1-ylalkyl)-3-oxoisothiazolo $[5,4-b]$ pyridines as CNS and antimycobacterial agents. Pharmazie 55:416-425

6. Malinka W, Świątek P, Filipek B, Sapa J, Jezierska A, Koll A (2005) Synthesis, analgesic activity and computational study of new isothiazolopyridines of Mannich base type. Farmaco 60:961-968

7. Malinka W, Świątek P, Śliwińska M, Szponar B, Gamian A, Karczmarzyk A, Fruziński A (2013) Synthesis of novel isothiazolopyridines and their in vitro evaluation against Mycobacterium and Propionibacterium acnes. Bioorg Med Chem 21:5282-5291

8. Baggaley K, English P, Jennings J, Morgan B, Nunn B, Tyrrell AW (1985) Inhibitors of blood platelet aggregation. Effects of some 1,2benzisothiazol-3-ones on platelet responsiveness to adenosine diphosphate and collagen. J Med Chem 28:1661-1667

9. Ünlü S, Baytas SN, Kupeli E, Yesilada E (2003) Studies on novel 7acyl-5-chloro-2-oxo-3H-benzoxazole derivatives as potential analgesic and anti-inflammatory agents. Arch Pharm 336:310-321

10. Gulcan HO, Kupeli E, Ünlü S, Yesilada E, Sahin MF (2003) 4-(5chloro-2 (3H)-benzoxazolon-3-yl) butanoic acid derivatives: synthesis, antinociceptive and anti-inflammatory properties. Arch Pharm 336:477-482

11. Gaussian 09, Revision C.1, M. J. Frisch, G. W. Trucks, H. B. Schlegel, G. E. Scuseria, M. A. Robb, J. R. Cheeseman, G. Scalmani, V. Barone, B. Mennucci, G. A. Petersson, H. Nakatsuji, M. Caricato, X. Li, H. P. Hratchian, A. F. Izmaylov, J. Bloino, G. Zheng, J. L. Sonnenberg, M. Hada, M. Ehara, K. Toyota, R. Fukuda, J. Hasegawa, M. Ishida, T. Nakajima, Y. Honda, O. Kitao, H. Nakai, T. Vreven, J. A. Montgomery, Jr., J. E. Peralta, F. Ogliaro, M. Bearpark, J. J. Heyd, E. Brothers, K. N. Kudin, V. N. Staroverov, R. Kobayashi, J. Normand, K. Raghavachari, A. Rendell, J. C. 
Burant, S. S. Iyengar, J. Tomasi, M. Cossi, N. Rega, J. M. Millam, M. Klene, J. E. Knox, J. B. Cross, V. Bakken, C. Adamo, J. Jaramillo, R. Gomperts, R. E. Stratmann, O. Yazyev, A. J. Austin, R. Cammi, C. Pomelli, J. W. Ochterski, R. L. Martin, K. Morokuma, V. G. Zakrzewski, G. A. Voth, P. Salvador, J. J. Dannenberg, S. Dapprich, A. D. Daniels, Ö. Farkas, J. B. Foresman, J. V. Ortiz, J. Cioslowski, and D. J. Fox, Gaussian, Inc., Wallingford CT, 2009.

12. Becke AD (1993) Density-functional thermochemistry III. The role of exact exchange. J Chem 98:5648-5652
13. Lee C, Yang W, Parr RG (1988) Development of the colle-salvetti correlation-energy formula into a functional of the electron density. Phys Rev B37:785-789

14. Perdew JP, Wang Y (1992) Accurate and simple analytic representation of the electron-gas correlation energy. Phys Rev B45:13244-13249

15. Adamo C, Barone V (1999) Toward reliable density functionals without adjustable parameters: the PBE0 model. J Chem Phys 110:61586170

16. Zawisza T, Malinka W (1985) Farmaco 40:124 